\title{
Impact of intracranial pressure measurement on survival in patients with severe traumatic brain injury
}

\author{
Krbila $\mathrm{S}^{1}$, Waczulikova $\mathrm{I}^{2}$, Sobona $\mathrm{V}^{1}$, Zahorec $\mathrm{R}^{3}$ \\ Department of Anesthesiology and Intensive Care Unit, Faculty Hospital, Nové Zámky, Slovakia. \\ stefan.krbila@gmail.com
}

\begin{abstract}
Objective: The aim of the study was to assess (i) a group of patients with established intracranial pressure (ICP) sensor in severe brain injuries scoring 3 points of Glasgow Coma Scale, (ii) mortality and survival of the patients within periods of 7, 30, 180 and 270 days; and (iii) predictive value of intracranial pressure and cerebral perfusion pressure for short and long-term survival of patients with traumatic brain injury.

Material and methods: The group consisted of 61 patients with trauma brain injury scoring 3 points of Glasgow Coma Scale, continuously monitored for intracranial pressure cerebral perfusion pressure at the Intensive Care Unit setting in Nové Zámky. Follow-up period was between 7 and 270 days. Measured values and other recorded data were analysed using methods of descriptive and inferential statistics.

Results: ICP values below $20 \mathrm{mmHg}$ were associated with a significantly lower risk of death of an individual patient at particular time. Accordingly, cerebral perfusion pressure values above $70 \mathrm{mmHg}$ during $0-2$ days were associated with a significantly higher long-term survival. Overall mortality rates within 30 days showed no peaks on survival curves. In the periods of 0-7 days, within 30 days, and between 30 and 180 days we recorded 24, 51 and 2 deaths, respectively. In the period between 180 and 270 days, mortality was zero.

Conclusion: The survival of trauma brain injury patients depends on the speed and quality of pre-hospital care and adequate follow-up treatment at specialized intensive care units. High levels of intracranial pressure and low cerebral perfusion pressure values in the early period after brain injury are closely related to mortality of patients within 30 days. Intracranial pressure monitoring may help to avoid problems and allow intervention before they become life-threatening (Tab. 4, Fig. 4, Ref. 23). Text in PDF www.elis.sk.

Key words: craniocerebral trauma, intracranial pressure monitoring, survival analysis, prediction of neurologic outcome, traumatic brain injury.
\end{abstract}

In 1960's, Lundberg published works dealing with intracranial pressure (ICP) monitoring, which were followed by establishing standardized terapeutic procedures for ICP measurement that were considered to reduce the extent of secondary post-traumatic brain injury (1).

In 1996, for the first time, uniform procedures for diagnosing and treating severe craniocerebral injuries were suggested and published by American Association of Neurological Surgeons and Trauma Brain Injury Foundation (2).

Brain injury is frequently associated with polytrauma, which greatly affects the survival of patients. The most common causes of brain injuries are traffic accidents, falling from heights, gunshot wounds, and work-related accidents.

${ }^{1}$ Department of Anesthesiology and Intensive Care Unit, Faculty Hospital, Nové Zámky, Slovakia, ${ }^{2}$ Division of Biomedical Physics, Faculty of Mathematics, Physics and Informatics, Comenius University, Bratislava, Slovakia, and ${ }^{3}$ 2nd Department of Anesthesiology and Intensive Care Unit, Faculty of Medicine, Comenius University, Bratislava, and St. Elizabeth's Cancer Institute, Bratislava, Slovakia

Address for correspondence: S. Krbila, MD, Department of Anesthesiology and Intensive Care Unit, Faculty Hospital, Slovenská 11/A, SK-940 34 Nové Zámky, Slovakia.

Acknowledgement: This study was partially supported by a scientific grant MZ SR 2007/29-UK-06 and by grant KEGA 003UK-4/2012 from the Cultural and Educational Grant Agency of the Ministry of Education in Slovakia.
Among the experts, there is a common perception of lack of definite data on the benefit from ICP monitoring because monitoring is not routinely performed in most of intensive care unit (ICU) centres worldwide. The main reason is that ICP monitoring is not without risks and errors such as incorrect probe placement, collapsed ventricular areas, the possibility of intracranial haemorrhage, or mechanical failure of ICP sensor (3). The risk of infection associated with insertion of the sensor is $6-11 \%$ in case of using sensor for over 6 days $(3,4)$. The incidence of bacterial colonization of intraparenchyme sensor with no clinical signs of infection is $10 \%$ (4). However, it was reported that mortality and clinical outcome in severe brain injury did not differ significantly between the groups with and without sensor (5).

The aim of this prospective study was to verify the predictive value of the dynamics of ICP and cerebral perfusion pressure (CPP) on survival in patients with severe trauma brain injury (TBI) in both short and long term.

\section{Patients and methods}

In this prospective and comparative study, we have analysed clinical data of all patients with craniocerebral trauma who were hospitalized at our clinic between 1.1.2007 and 31.12.2010. The patients were transported to the clinic either directly from the scene 
Tab. 1. Age distribution.

\begin{tabular}{|c|c|c|c|c|c|c|}
\hline & \multicolumn{2}{|c|}{ Total (T) } & \multicolumn{2}{|c|}{ Dead (D) } & \multicolumn{2}{|c|}{ Survived (S) } \\
\hline & 1. subpopulation & 2. subpopulation & 1. subpopulation & 2. subpopulation & 1. subpopulation & 2. subpopulation \\
\hline Count & 18 & 43 & 15 & 38 & 3 & 5 \\
\hline Medián & 22.5 & 54 & 22 & 54 & 31 & 55 \\
\hline lower quartile & 19 & 48 & 19 & 47 & 27 & 53 \\
\hline upper quartile & 27 & 63 & 25 & 63 & 34 & 57 \\
\hline
\end{tabular}

of an accident or immediately after having been diagnosed with craniocerebral trauma in another hospital. All these patients were in coma, scored GCS 3, and in need of lung ventilation and urgent neurosurgical intervention. The patients admitted from the scene had immediately taken $\mathrm{CT}$ examination. According to the $\mathrm{CT}$ result the patient underwent neurosurgical intervention or conservative treatment that included insertion of ICP sensor. The monitoring of ICP and CPP was being done for 7 days as long as the patient survived. Of 61 patients of the cohort group, 40 patients underwent neurosurgical intervention. CT scan was repeated in 12-24 hours after surgery. In case of high ICP values with no response to treatment, CT was performed immediately. Examination was performed within 12 hours from the surgery and re-examination according to the outcome of previous one or according to the clinical condition. The study was approved by the Ethics Committee of Faculty Hospital in Nove Zamky. Methods of monitoring and clinical procedures were used as follows:

- Insertion of ICP sensor, continuous measurement of ICP, CPP, body temperature

- Continuous invasive measurement of arterial pressure (AP)

- Regular measurement of central venous pressure

- Regular evaluation of GCS, neurological status

- Evaluation of period of hospitalisation, lethality

- Evaluation of neurological status by GOS after 7, 30, 180 and 270 days.

These parameters used for evaluating the parameters of neurological status: GCS, GOS, ICP, as well as those of hemodynamics: CPP and mean arterial pressure (MAP).

For continuous ICP monitoring we used a CODMAN parenchymatose sensor (Johnson and Johnson) that was connected to a calibrated bed-side monitor of vital functions.

\section{Statistical analysis}

Clinical data of patients $(n=61)$ were tested for normality using a Shapiro-Wilk test. The normally distributed characteristics are described as the mean \pm standard deviation (SD). Alternatively we report median with the lower and upper quartiles. For categorical variables we indicate absolute or relative (\%) frequencies. Unpaired test was used for testing for differences between the group of dead (D, $\mathrm{n}=53 ; 86.9 \%)$ and survived patients $(\mathrm{S}, \mathrm{n}=8 ; 13.1 \%)$ in the selected normally distributed variables at the given time. Otherwise, we used a nonparametric Mann-Whitney U test. Categorical variables were tested with a test for two binomial independent proportions.

The assumption that ICP and CPP are mutually correlated was confirmed with simple linear regresion and Pearson correlation coeficient (r). Dynamics of ICP and CPP changes in time (ICP and CPP time plots) in D and $\mathrm{S}$ groups were tested with one-way analysis of variance (ANOVA) with replication. Differences be- tween the time-course curves for D and $\mathrm{S}$ groups were tested on the null hypothesis whether all data sets share the same parameters. The curves were compared with the extra-sum-of-squares F-test yielding a $\mathrm{P}$ value for nested model.

The relationships between potential predictors and survival were analysed by a multiple logistic regression. Clinically relevant predictors are characterised by OR (odds ratio value), which express the chance of survival for a unit change in the given characteristics. The quality of model was established by goodness-of-fit chi ${ }^{2}$ test whilst the significance of the whole model by likelihood ratio chi ${ }^{2}$-test.

Survival rates in both investigated D and S groups were estimated with unconditional Kaplan-Meier survival method and characterised by the median of survival together with respective $95 \%$ confidence intervals ( $95 \% \mathrm{CI}$ ). Differences between the plots of survival for both D and S groups were tested by log-rank test. Results are presented as respective survival plots and betweengroup survival differences were examined by long-rank test in Peto-Prentice modification.

All $p$ values cited are two-sided alternatives; differences resulting in a $p$ value of less or equal to 0.05 were declared statistically significant $(6,7)$.

For statistical analysis, we employed the software StatsDirect ${ }^{\circledR}$ v.2.7.8 (StatsDirect Sales, Sale, UK) and GraphPad Prism 5 (GraphPad Software, San Diego, CA, USA).

\section{Results}

\section{Characteristics of the patients and descriptive statistics}

A total of 61 patients were processed in the given period, with female gender proportion $(11 ; 18 \%)$ significantly different from that of male gender $(50 ; 82 \%),(p<0.0001)$. This difference can be unequiv-

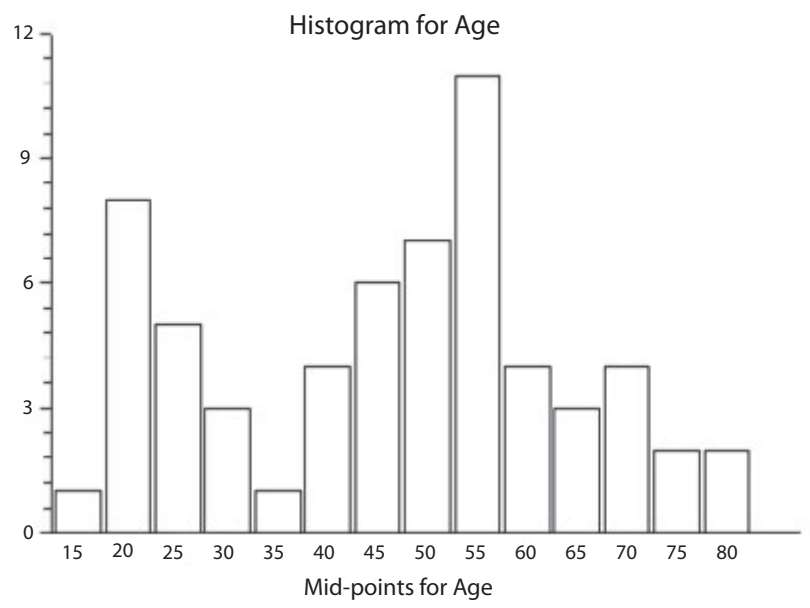

Fig . 1. Age distribution of patients. 
$696-701$

ocally attributed to the inherent heterogeneity in human behaviour, i.e. to more frequent risk taking among men than among women.

Eight patients (subgroup S, 13.1\%), survived the period of 270 days, all being of male gender. Fifty three patients died (subgroup D; $86.9 \%$ ); 42 men and 11 women.

The age distribution of patients has exhibited a bimodal shape, which clearly indicates two subpopulations with a point of separation at about $35 y$ (Fig. 1). This distribution plot consists of two approximately normal distributions (tested by a Shapiro-Wilk test), the first maximum is between 22-23 y and the second in $54 \mathrm{y}$ (Tab. 1).

Medians, as representative values of age in subgroups D and $\mathrm{S}$ are not significantly different from values that characterised the whole group of patients $(\mathrm{T})$. Bimodality can be attributed to the same cause that we have suggested for the uneven proportion of genders.

\section{Analysis of recorded ICP and CPP values}

Since the calculation of CPP is based on ICP value, first we have tested the tightness of the relationship between ICP and CPP and, thus the reliability of predictions of CPP from ICP. Given that the area of clinical interest has been focused on the early period after the accident, we present an analysis of averaged values of ICP and CPP from zero to second day from injury. Because of the high mortality within the first 7 days and consequential rapid decrease in number of patients in sample, this model estimate is most accurate for prediction, i.e. with the narrowest $95 \%$ prediction interval (Fig. 2). We confirmed a high degree of negative correlation $(r=-0.77 ; \mathrm{p}<0.0001)$. Regression function for prediction of CPP is expressed by equation (1):

$$
\mathrm{CPP}_{0-2}=-0.95 \mathrm{ICP}_{0-2}+80.04
$$

The dynamics of the monitored ICP and CPP values in the early period after injury is reported in Table 2, separately for patients who did not (group D) and did survive (group S) the period of 180 days. ICP and CPP values represent a mean value of all measurements taken from the patients surviving the given day. Between-

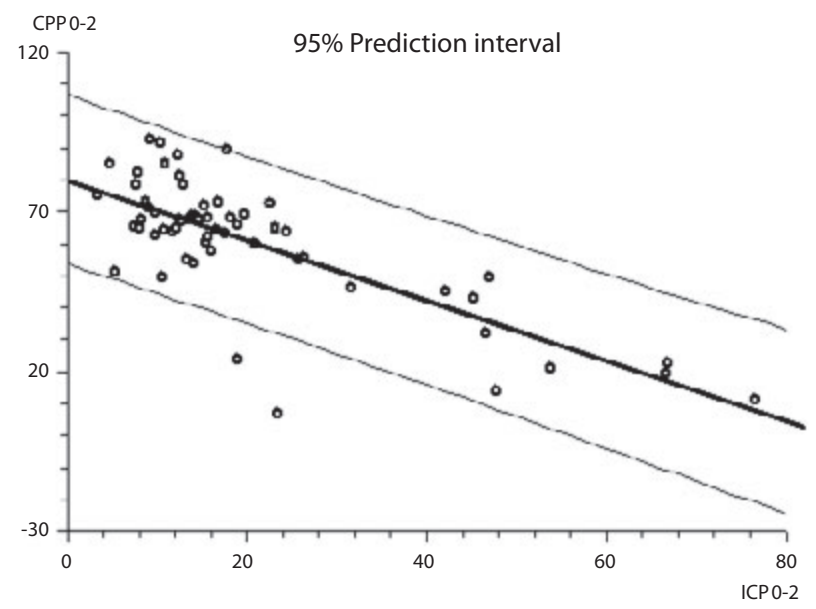

Fig. 2. Graph of simple linear regression of cerebral perfusion pressure (CPP) on intracranial pressure (ICP), with the $95 \%$ prediction interval.
Tab. 2. Dynamics of changes in ICP and CPP in the patients with traumatic brain injury.

\begin{tabular}{|c|c|c|c|c|}
\hline \multirow{2}{*}{ Day } & \multirow{2}{*}{$\begin{array}{c}\text { Variable } \\
\mathrm{mmHg}\end{array}$} & \multicolumn{2}{|c|}{ Group } & \multirow{2}{*}{$P$ value } \\
\hline & & $\mathrm{D}$ & $\mathrm{S}$ & \\
\hline \multirow{2}{*}{$0-1$} & ICP & 21.6 & 16.2 & 0.052 \\
\hline & CPP & 59.1 & 68.8 & 0.023 \\
\hline \multirow{2}{*}{2} & ICP & 23.1 & 14.1 & 0.011 \\
\hline & CPP & 63.6 & 76.2 & 0.040 \\
\hline \multirow{2}{*}{3} & ICP & 21.3 & 14 & 0.047 \\
\hline & CPP & 64.8 & 77.7 & 0.018 \\
\hline \multirow{2}{*}{4} & ICP & 19.3 & 13.9 & 0.215 \\
\hline & CPP & 65.9 & 83 & 0.013 \\
\hline \multirow{2}{*}{5} & ICP & 17.9 & 14.1 & 0.334 \\
\hline & CPP & 65 & 89.4 & 0.002 \\
\hline \multirow{2}{*}{6} & ICP & 16.8 & 14.4 & 0.427 \\
\hline & CPP & 66.7 & 82.5 & 0.074 \\
\hline \multirow{2}{*}{7} & ICP & 16.5 & 11.5 & 0.368 \\
\hline & CPP & 69.1 & 79.1 & 0.266 \\
\hline
\end{tabular}

group differences in ICP and CPP recorded in the early period after injury (during the first two days) were significant $(p<0.05)$. Since mortality in the time frame of 7 days from traumatic event is high and the sharply declining number of patients in the sample compromises the power of testing the differences, reliable estimates of the differences between groups D and $\mathrm{S}$ in later periods can only be obtained on the extended database of patients. However, the comparison of curves as a whole on a statistical basis using nonlinear fitting and extra-sum-of-squares F-test yielded different bestfit values of the model parameters and P value of less than 0.0001 , respectively. These results indicate that the differences between the curve profiles for $\mathrm{D}$ and $\mathrm{S}$ groups were big enough to distinguish the groups as different with respect to the recorded ICP and CPP.

Notably, in the first two days, the plots of time records of ICP values in groups $\mathrm{D}$ and $\mathrm{S}$ show different profiles (Fig. 3a). This divergence is not reflected in CPP profiles (Fig. 3b). Presumably the reason is that CPP is a complex parameter composed of two measurements taken from a patient, each of them bringing specific information about the current patient's condition (2).

$\mathrm{CPP}=\mathrm{MAP}-\mathrm{ICP}$

Our results (Tab. 2) did confirm the suggestions made by other groups of investigators (8) that ICP values above $20 \mathrm{mmHg}$ have a huge negative impact on the survivability of brain-injured patients. In order to verify this hypothesis on our sample, we stratified the patients into two subgroups, one with an initial ICP (ICP $\left.{ }_{\text {in }}\right)$ less than $20 \mathrm{mmHg}$ (denoted as 0 ) and the other with that greater than or equal to $20 \mathrm{mmHg}$ (denoted as 1). Although with low value of probability ( $\mathrm{p}=0.11$ ), we found that the proportions of patients between $\mathrm{D}$ and $\mathrm{S}$ groups (Tab. 3) were not significantly different. This indicates that there is the possibility of type-two error, i.e. that the low number of patients in group $\mathrm{S}$ precludes the revealing existing difference. Despite the fact that we found a high degree of relative risk of death in patients with ICP above $20 \mathrm{mmHg}(\mathrm{OR}=3.6)$, we have to consider this result as inconclusive. Therefore, it is advisable to proceed, and extend the database of TBI patients.

Time courses of day-averaged ICP and CPP during the whole 


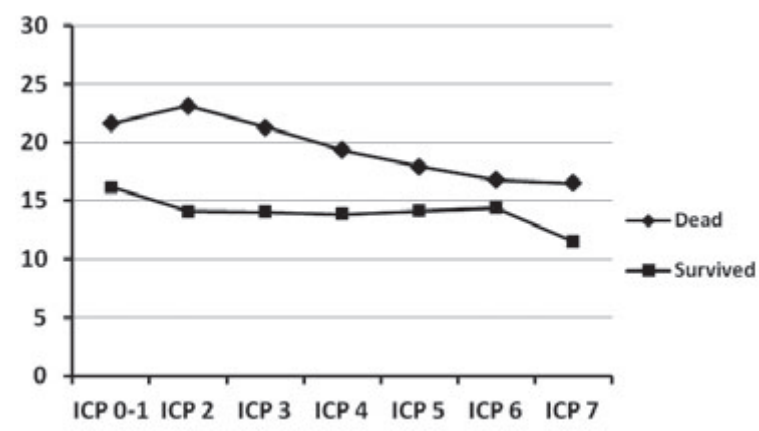

Fig. 3a. The time course of intracranial pressure (ICP/mmHg) in the group of non-survived (D) and survived (S) patients (zero and the first day are averaged for the imbalance of measurements in the number of records during the day of admission.

monitoring period (maximum 7 days for a single patient) in subgroups $\mathrm{ICP}_{\text {in }} 1$ and $\mathrm{ICP}_{\text {in }} 0$ are presented in Table 4.

Analysis of the impact of ICP and CPP on the patient mortality

With a logistic regression tool, we first verified whether the average ICP or CPP monitored over a period of $0-2$ days from the accident would contribute significantly to the prediction of mortality. We found that CPP is a stronger predictor of the outcome (death within 180 days from the traumatic event) than $\operatorname{ICP}(p=0.0007$ vs 0.32 , respectively). The overall model of prediction was highly significant $(\mathrm{p}<0.0001)$, and odds ratio below unit $(\mathrm{OR}=0.86 ; 95 \%$ CI: $0.79-0.94)$ is confirming the expected negative relationship between CPP value and risk of death. Qualitatively, the same result was obtained for the model with mean CPP for the whole monitoring period (maximum 7 days for each patient). We also proved that neither age nor gender is a significant predictor ( $\mathrm{p}=0.79$ and 0.99 , respecively). Therefore, it does not make sense to include them into the predictive model.

Tab. 3. Overall mortality after 270 days according initial ICP during days 0-1 (first 24 hours).

\begin{tabular}{lcc}
\hline$(\mathrm{n}=61)$ & $\mathrm{ICP}_{\text {in } 1}$ & $\mathrm{ICP}_{\text {in } 0}$ \\
\hline $\mathrm{D}$ & 18 & 35 \\
$\mathrm{~S}$ & 1 & 7 \\
\hline
\end{tabular}

Tab. 4. Course of ICP and CPP during the first 7 ICU days.

\begin{tabular}{ccccc}
\hline \multirow{2}{*}{ Day } & Variable & \multicolumn{2}{c}{ Group } & \multirow{2}{*}{ P value } \\
\cline { 3 - 4 } & mmHg & ICPin 1 & ICPin 0 & \\
\hline \multirow{2}{*}{$0-1$} & ICP & 37.2 & 11.5 & $<0.001$ \\
& CPP & 39.3 & 68.2 & $<0.001$ \\
\hline \multirow{2}{*}{2} & ICP & 43.3 & 13 & $<0.001$ \\
& CPP & 45.8 & 73.5 & $<0.001$ \\
\hline \multirow{2}{*}{3} & ICP & 40.8 & 13.1 & $<0.001$ \\
& CPP & 48.5 & 73.1 & 0.006 \\
\hline \multirow{2}{*}{4} & ICP & 34.4 & 13.5 & $<0.001$ \\
& CPP & 49.6 & 74.7 & 0.002 \\
\hline \multirow{2}{*}{5} & ICP & 33.5 & 12.4 & $<0.001$ \\
& CPP & 47.8 & 74.9 & 0.005 \\
\hline \multirow{2}{*}{6} & ICP & 30.5 & 12.5 & $<0.001$ \\
& CPP & 50.2 & 74.2 & 0.018 \\
\hline \multirow{2}{*}{7} & ICP & 30.5 & 10.9 & $<0.001$ \\
& CPP & 42.2 & 80.1 & 0.002 \\
\hline
\end{tabular}

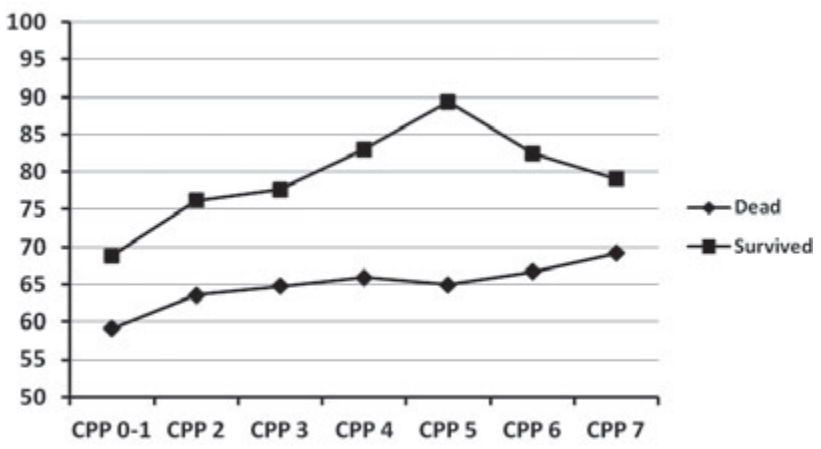

Fig. 3b. Dynamics of changes in cerebral perfusion pressure (CPP/ mmHg) in non-survived (D) and survived (S) patients (zero and the first day are averaged for the imbalance of measurements in the number of records during the day of admission.

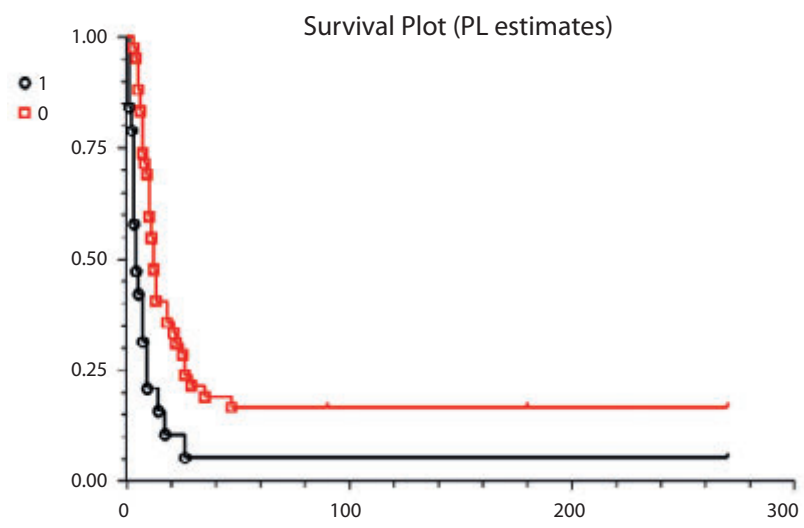

Fig. 4. Estimated survival curves for patients in groups $\operatorname{ICP}_{\text {in }} 1$ (identifier 1) and ICP 0 (identifier 0). Censorship is marked with vertical tics and death times with circles and squares for $\operatorname{ICP}_{\text {in }} 1$ and $\operatorname{ICP}_{\text {in }} 0$ groups, respectively.

Survival rates in the brain-injured patients stratified according to ICP values at admission

Differences in survival rates between subgroups $\mathrm{ICP}_{\text {in }} 1$ and $\mathrm{ICP}_{\text {in }} 0$ were analysed using Kaplan-Meier survival method. Kaplan-Meier's estimate of median survival in the whole sample investigated in period 2007-2010 was 10 days (95\% CI: 7.4-12.5). For the patients with $\mathrm{ICP}_{\text {in }}$ above $20 \mathrm{mmHg}$ (group 1), the median survival time was 4 days (95\% CI: $1.2-6.8$ ), and for those with $\mathrm{ICP}_{\text {in }}$ below $20 \mathrm{mmHg}$ (group 0) it was 12 days (95\% CI: 9.6-14.4). This between-group difference in survival (Fig. 4) was highly significant $(\mathrm{p}<0.0001)$. Hazard ratio for $\mathrm{ICP}_{\text {in }} 1$ compared to $\mathrm{ICP}_{\text {in }} 0$ amounted to 2.3 (95\% CI: $\left.1.14-4.60\right)$.

We can conclude that the initial ICP value below $20 \mathrm{mmHg}$ was associated with a significantly longer survival in patients with brain injury.

\section{Discussion}

Numerous investigations have shown that raised ICP and a fall in arterial pressure in TBI patients are associated with a poor prognosis $(8,9)$. Raised ICP contributes to inadequate CPP 
$696-701$

(less than $70 \mathrm{mmHg}$ ), which has been shown to be a major factor in high mortality of patients, and in addition, the advances in the effective treatment of high ICP have been shown to lead to a decline in mortality rates (10). Thus, the assessment of CPP is vital and possible, either by measurement of both ICP and MAP, or by measuring MAP and making a reasonable estimate for ICP. Therefore it would be optimal to have a possibility of precise ICP measuring. The first reference to the clinical use of continuous monitoring of intracranial pressure has emerged in 1960's (11). Obviously, the understanding of principles of ICP measurement is an important prerequisite for its effective and safe clinical use. At present, guidelines for the indications of ICP monitoring do exist, and they have become a recommended procedure, particularly in the management of patients with acute coma due to severe brain injury, or it is assumed that along with the introduction of ICP monitoring, mortality related to brain injuries has significantly decreased $(5,12)$. Nevertheless, ICP monitoring is still considered to be an invasive tool with the risk of developing additional serious complications (12) reported in our previous work (13).

Even though we have failed to prove a significant difference in 30-day survival between ICP-monitored and not monitored patients (13), the findings have pointed to the notion that the patients with ICP values below $20 \mathrm{mmHg}$ were at reduced risk of death, or vice versa, the levels above $20 \mathrm{mmHg}$ significantly increased the risk of death within 30 days after brain traumatic event. Therefore, in the present study we have analysed clinical data and outcomes of 61 ICP-monitored patients in detail. The median survival of the investigated sample that was followed for up to 270 days, was 10 days. Among 61 patients, 24 patients died within the first 7 days, and 51 patients died in the period of 30 days from the injury. Between day 30 and day 180, only two patients died, and between day 180 and day 270, no death was observed. With the number of patients in the database being still relatively low, the counts of events (deaths) in single times do not allow for more reliable estimate of the survival rates for the specified times. We certainly recommend continuing the study, and gathering more data.

The main clinically relevant finding in our study was the significantly higher survival rate of patients with ICP below $20 \mathrm{mmHg}$ with median survival of 12 days, in comparison with only 4 days for those with ICP equal or above $20 \mathrm{mmHg}$. A logistic regression analysis showed that average values of ICP and CPP recorded in the period of 0-2 days from the accident contributed to the prediction of mortality within 180 days after injury. We found that CPP is a stronger and statistically significant predictor of the outcome (death within the given period) than ICP. Obviously, the CPP value, which is defined as the difference between mean arterial pressure and intracranial pressure, conveys more specific and complex information about the patient's current condition. To estimate a patient's CPP reliably we need to know the patient's ICP as precisely as possible. ICP monitoring provides the only sure way of confirming intracranial hypertension. If increased ICP is not present, the treatment potentially dangerous for that patient can be avoided. If the patient is in acute coma or sedated, the conventional neurological examination is useless. It is then that ICP monitoring provides a means of determining the patient's CPP and index of cerebral function (14). Thus we support the view that if hypertension is suspected, present, or persistent, a continuous measurement of ICP provides an early opportunity of assessing whether therapy works, as well as allows the team caring for the patient to quickly and efficiently respond to elevations in ICP to various stimuli, or switch to an alternative therapy if the treatment is ineffective. Namely, continuous ICP monitoring allows taking control CT scan early enough, and deciding between neurosurgical or aggressive conservative treatment focused on effective reduction in ICP. There is a relation between ICP, CPP and MAP (2), namely if ICP is raised, a fall in blood pressure must be avoided or treated quickly to maintain MAP values at levels that would keep CCP above $70 \mathrm{mmHg}$. As we have shown in Figure 3a, ICP values above the critical value of $20 \mathrm{mmHg}$ were associated with a poor cerebral outcome and consequently with death. Just as maintaining low ICP, it is important to prevent a fall in CPP below $70 \mathrm{mmHg}$, as we have found out that decreased CPP shortly after injury significantly distinguished the group of non-surviving patients from those surviving the period of 180 days (Fig. 3b). A novel finding in our work is the evidence that according to the current data statistical analysis (Fig. 4), the predictive value of CPP dynamics recorded in the first $24-48$ hours after the accident was higher than that of ICP, although these values are interrelated (1). This supports the importance of CPP maintenance as stressed by other studies, although some authors suggest that CPP values under $60 \mathrm{mmHg}$ may still be sufficient to ensure a good survivability in some patients with good CNS autoregulation as long as the required monitoring of cerebral oximetry and brain metabolism is provided (15). Because we did not use cerebral oximetry, we have preferred to set the secure threshold at $70 \mathrm{mmHg}$ in order to prevent potential cerebral ischaemia resulting from lower levels of ICP. According to Guidelines for the Management of Severe TBI, the critical survival limits of CPP are between $50-60 \mathrm{mmHg}$ (16). Balestri et al (17) have set the cut-off point at $60 \mathrm{mmHg}$ and reported a significantly increased mortality when CPP values fell below that value. Accordingly, maintaining CPP above $60 \mathrm{mmHg}$ significantly raised the survival rates of patients. Contrary to expectations, CPP values above $95 \mathrm{mmHg}$ did not improve further the survival of patients with craniocerebral trauma in their study. White and Venkatesh also expressed an opinion that maintaining CPP between 50 and $70 \mathrm{mmHg}$ is acceptable providing that cerebral oximetry monitoring is also performed, however, they stress that keeping CPP in the accepted range is just one aspect of complex trauma care at ICU (18). Mortality of patients with severe brain injury and GCS less than 8 points still remains high. The reported data in prospective and retrospective studies range from $50 \%$ to $100 \%$. Chamoun et al have found $49.2 \%$ mortality among 189 patients with GCS of 3 (19). Fearnside et al report a 65 $\%$ mortality in patients with craniocerebral trauma scored GCS 3 (20). Further, in their 2006 retrospective study, Tien et al published an overall mortality of $76.8 \%$, however, all patients with severe brain injury and haemorrhage died (21). Similarly, high mortality rates of $89 \%$ and $64 \%$ were found in a study involving 111 patients with CNS haemorrhage and epidural haematoma carried out by Kotwica et al (22), and in that involving 117 patients and 
carried out by Waxman et al (23), respectively. With $\mathrm{GOS}=1,10$ patients survived, with GOS=2, 3 of them (23).

Apparently, the above mentioned results and published outcomes indicate that it is highly desirable to have a tool that would be able to distinguish reliably the patients predisposed to trauma treatment failure. Presumably a combination of significant predictors of the primary outcome (survival) measured in the early stages creates simple predictive models that allow identifying the most endangered patients. The reliability of these models can be increased by extending the patient database. A major limit of this prospective study was a low number of eligible patients, which does not allow for better-founded conclusions. Nevertheless, the assets possessed in our study include the prospective character, longer period of collecting cases (4 years) and longer follow-up of patients after their release from hospital care (180-270 days). Our results have indicated that ICP and CPP were major predictors of early and late mortality rates in severe brain injury (among patients with GCS of 3). In conclusion, we feel it worthwhile to comment on our observation of higher prevalence of TBI in male gender and that of a two-peak (bimodal) distribution for age at brain trauma occurence, which is interesting from an epidemiological point of view. Both observations represent a knowledge base for recognising subpopulations that are at greater risk of death from head trauma. With such high mortality rates among brain-injured patients, there is an obvious and urgent need to pursue effective strategies and educational programs that can reduce risk-taking behaviours, and thus prevent serious injuries from occurring. The latter finding strengthens the point that reliable predictive models based on both, clinical and epidemiological data, would be of great value in developing these strategies and programs. We hope this finding provides the epidemiologists, especially those working in trauma prevention, with ideas about how to incorporate this information into their work.

\section{Conclusion}

The aim of this prospective clinical study was to determine, whether improving the management of a comprehensive neurointensive treatment based on monitoring the intracranial pressure would positively affect the clinical course and outcome, as well as increase the chances for patients to return to society with as little permanent disability as possible. The mortality of severe TBI (GCS 3) remains very high. Most patients die in two frame windows, either shortly after the causing event, or in 30 days from it. High level of intracranial pressure (ICP $>20 \mathrm{mmHg}$ ) and low cerebral perfusion pressure (CPP $<65 \mathrm{mmHg}$ ), which cannot be effectively treated at ICU, are the main indicators of poor outcome in brain-injured patients. Low value of cerebral perfusion pressure ( $\mathrm{CPP}<65 \mathrm{mmHg}$ ) during the first two days is a significant predictor of early and late mortality rates, and thus a better candidate for developing a predictive risk model for outcomes after brain injury. Since our analysis was confronted with a discrepancy between required and available data, we recommend further data gathering to allow for sound evaluation of ICP-monitoring benefits for traumatic brain injury patients.

\section{References}

1. Lundberg N. Continuous recording and control of ventricular fluid pressure in neurosurgical practice. Acta Psychol Neur Scand 1960; 36 (Suppl): 1-193.

2. Bullock MR, for the Task Force. Indications for intracranial pressure monitoring. In: Management and prognosis of severe traumatic brain injury. Part I: Guidelines for the management of severe traumatic brain injury. J Neurotrauma 2007; 24 (Suppl 1): 37-44.

3. Ghajar J. Intracranial pressure monitoring techniques. New Horiz 1995; 3: 395-398.

4. Mayhall CG, Archer NH et al. Ventriculostomy- related infections: A prospective epidemiologic study. N Engl J Med 1984; 310: 553-559.

5. Martinez-Maňas R.M, Santamaria D. Intracranial pressure monitor: Prospective study of accuracy and complications. J Neurol Neurosurg Psychiat 2000; 69: 82-86.

6. Waczulikova I, Slezák P. Statistics in Medical Research. Radiology IV: Uroradiology (in Slovak). Bratislava: Veda, 2009.

7. Gaško R, Slezák P, Waczulíková I, Gašková Z. Rozumieme štatistickým výsledkom odborných publikácií? Otázky a odpovede. Cassonic s.r.o., Košice, 2010, 70 pp. ISBN 978-80-970581-2-8. 08.

8. Bouma GJ, Muizelaar JP, Bandoh K et al. Blood pressure and intracranial pressure-volume dynamics in severe head injury: relationship with cerebral blood flow. J Neurosurg 1992; 77: 15-19.

9. Marmarou A, Anderson RL, Ward JD et al. Impact of ICP instability and hypotension on outcome in patients with severe head trauma. J Neurosurg 1991; 75: S59-S66.

10. Hayden White, Bala Venkatesh: Cerebral Perfusion In Neurotrauma: A Review. Anesthesia\&Analgesia 2008; 107: 979-988.

11. Guillame J, Janny P. Continuous intracranial manometry: physiopathologic and clinical significance of the method. Presse Med 1951; 59: 953-955.

12. Sahipaul R, Girotti M. Intracranial pressure monitoring in severe traumatic brain injury-results of Canadian survey. Can J Neurol Sci 2000; 27: 143-147.

13. Krbila Š, Soboňa V, Waczulikova I, Zahorec R. Does measuring the intracranial pressure influence survival rates in patient with brain injury? Anest Intenziv Med 2011; 22; 5:272-278.

14. Intracranial pressure monitoring by Brian North, in Head Injury. Edited by Peter Reilly and Ross Bullock. Published in 1997 by Chapman \& Hall, London.

15. Ralph JK, Lowes T. Neurointensive care. JR Army Med Corps; 155 (2): $122-174$.

16. Brain Trauma Foundation. Guidelines for the Management of Severe Traumatic Brain Injury. 3rd Edition. J Neurotrauma 2007; 24: S1-116.

17. Balestreri M, Czosnyka M, Hutchinson P, Steiner LA, Hiler M, Smielewski P, Pickard JD. Impact of Intracranial Pressure and Cerebral Perfusion Pressure on Severe Disability and Mortality after Head Injury. Neurocrit Care 2006; 04: 8-13.

18. White H, Venkatesh B. Cerebral Perfusion Pressure in Neurotrauma: A Review. Anesth Analg 2008; 107: 979-988.

19. Chamoun RB, Robertson CS, Gopinath SP. Outcome in patients with blunt head trauma and a Glasgow Coma Scale score of 3 at presentation. Clinical article J Neurosurg 2009; 111: 683-687.

20. Fearnside MR, Cook RJ, McDougall P, McNeil RJ. The Westmead Head Injury Project outcome in severe head injury. A comparative analysis of prehospital, clinical and CT variables. Br J Neurosurg 1997; 7: 267-279.

21. Tien HC, Cunha JR, Wu SN, Chughtai T, Tremblay LN, Brenneman FD et al. Do trauma patients with a Glasgow Coma Scale score of 3 and bilateral fixed and dilated pupils have any chance of survival? J Trauma 2006; 60: 274-278.

22. Kotwica Z, Jakubowski JK. Head-injured adult patients with GCS of 3 on admission - who have a chance to survive? Acta Neurochir (Wien) 1995; 133: 56-59.

23. Waxman K, Sundine MJ, Young RF. Is early prediction of outcome in severe head injury possible? Arch Surg 1991; 126: 1237-1242.

Received February 2, 2012. Accepted September 20, 2013 